\title{
PLGA nanofiber membranes loaded with epigallocatechin-3-O-gallate are beneficial to prevention of postsurgical adhesions
}

This article was published in the following Dove Press journal:

International Journal of Nanomedicine

22 August 2014

Number of times this article has been viewed

\author{
Yong Cheol Shin ${ }^{1, *}$ \\ Won Jun Yang ${ }^{1, *}$ \\ Jong Ho Lee' \\ Jin-Woo Oh \\ Tai Wan Kim ${ }^{3}$ \\ Jong-Chul Park ${ }^{4}$ \\ Suong-Hyu Hyon ${ }^{5}$ \\ Dong-Wook Han' \\ 'Department of Cogno-Mechatronics \\ Engineering, Pusan National \\ University, Busan, Republic of Korea; \\ ${ }^{2}$ Department of Nanomaterials \\ Engineering, College of Nanoscience \\ and Nanotechnology, Pusan National \\ University, Busan, Republic of Korea; \\ ${ }^{3}$ Department of Design, College of \\ Arts, Pusan National University, Busan, \\ Republic of Korea; ${ }^{4}$ Department of \\ Medical Engineering, Yonsei University \\ College of Medicine, Seoul, Republic \\ of Korea; ${ }^{5}$ Center for Fiber and Textile \\ Science, Kyoto Institute of Technology, \\ Kyoto, Japan \\ *These authors contributed equally \\ to this work
}

Abstract: This study concentrates on the development of biodegradable nanofiber membranes with controlled drug release to ensure reduced tissue adhesion and accelerated healing. Nanofibers of poly(lactic-co-glycolic acid) (PLGA) loaded with epigallocatechin-3-O-gallate (EGCG), the most bioactive polyphenolic compound in green tea, were electrospun. The physicochemical and biomechanical properties of EGCG-releasing PLGA (E-PLGA) nanofiber membranes were characterized by atomic force microscopy, EGCG release and degradation profiles, and tensile testing. In vitro antioxidant activity and hemocompatibility were evaluated by measuring scavenged reactive oxygen species levels and activated partial thromboplastin time, respectively. In vivo antiadhesion efficacy was examined on the rat peritonea with a surgical incision. The average fiber diameter of E-PLGA membranes was approximately 300-500 nm, which was almost similar to that of pure PLGA equivalents. E-PLGA membranes showed sustained EGCG release mediated by controlled diffusion and PLGA degradation over 28 days. EGCG did not adversely affect the tensile strength of PLGA membranes, whereas it significantly decreased the elastic modulus and increased the strain at break. E-PLGA membranes were significantly effective in both scavenging reactive oxygen species and extending activated partial thromboplastin time. Macroscopic observation after 1 week of surgical treatment revealed that the antiadhesion efficacy of E-PLGA nanofiber membranes was significantly superior to those of untreated controls and pure PLGA equivalents, which was comparable to that of a commercial tissue-adhesion barrier. In conclusion, the E-PLGA hybrid nanofiber can be exploited to craft strategies for the prevention of postsurgical adhesions.

Keywords: nanofiber membrane, poly(lactic-co-glycolic acid), epigallocatechin-3-O-gallate, antiadhesion, tissue-adhesion barrier

\section{Introduction}

An adhesion develops as a result of the wound healing process, where tissue repair mechanisms respond to any disturbance, such as surgery, trauma, infection, or radiation. ${ }^{1-3}$ Postsurgical abdominal adhesions and their sequelae present major clinical and medicoeconomic problems such as small bowel obstruction, injury at reoperations, female infertility, and chronic pain. ${ }^{4,5}$ Various types of barriers with the ability to reduce the adhesion formation are now available in the form of pharmacological and nonpharmacological agents, or a combination of these agents, applied between or over damaged tissue surfaces. ${ }^{6-8}$ Many different pharmacological agents, such as anti-inflammatory, fibrinolytic , and antiproliferative drugs, have been used in an effort to arrest the adhesion pathway or to tip the balance in the favor of fibrinolysis and fibrin deposition. ${ }^{9}$ A number of pharmacological agents were approved for human use, some of which later had to be withdrawn from the market due to safety concerns
Correspondence: Dong-Wook Han Department of Cogno-Mechatronics Engineering, Pusan National

University, Busandaehak-ro 63beon-gil,

Geumjeong-gu, Busan 609-735, Republic of Korea

Tel +825 I 9307725

Fax +82 5I 5I4 2358

Email nanohan@pusan.ac.kr
International Journal of Nanomedicine 2014:9 4067-4078

4067

Dovepress

http://dx.doi.org/10.2147/IJN.S68197 (c) (i) (5) 2014 Shin et al. This work is published by Dove Medical Press Limited, and licensed under Creative Commons Attribution - Non Commercial (unported, v3.0) BY LC License. The full terms of the License are available at http://creativecommons.org/licenses/by-nc/3.0/. Non-commercial uses of the work are permitted without any further permission from Dove Medical Press Limited, provided the work is properly attributed. Permissions beyond the scope of the License are administered by Dove Medical Press Limited. Information on how to request permission may be found at: http://www.dovepress.com/permissions.php 
or lack of efficacy. ${ }^{10}$ Nonpharmacological antiadhesion agents can broadly be categorized into two types; one is a site-specific agent forming mechanical or gel barriers, such as membranes or films, fibrous sheets, and meshes, and another is a broad-coverage fluid agent, ie, instillates like lactated Ringer's solution., ${ }^{9,10}$ A problem encountered with these agents is the necessity to decide intraoperatively where adhesions are likely to occur and, consequently, where to place the agents. ${ }^{6}$ The decision may be easy to make when there is only one injured site, but may be much more difficult in surgical patients with severe multiple injuries. Thus, an ideal agent should be easy to and ready to use and remain over injured surfaces for a limited period of time.

During the last few decades, considerable research has been conducted into the complex process of adhesion formation, and combined adhesion-prevention strategies have been investigated to develop optimal tissue-adhesion barriers. Hence, complete adhesion prevention remains an unsolved problem, and the search for an ideal antiadhesion agent is still ongoing. Thermosensitive hydrogels containing basic components of poly( $\varepsilon$-caprolactone, PCL) and poly(ethylene glycol, PEG) have been shown to effectively prevent postsurgical intra-abdominal adhesions. ${ }^{11,12}$ Moreover, nonwoven fibrous membranes, composed of biodegradable copolymers including poly(lactic-co-glycolic acid, PLGA), PLGA/PEG-poly(lactic acid, PLA) and polyurethane/PLGA, impregnated with antibiotic or anti-inflammatory drugs, have been examined previously in the context of adhesions in a rat model ${ }^{13-15}$ however, their use in combination with green tea polyphenol, epigallocatechin-3-O-gallate (EGCG), is novel and challenging. The direct impregnation of PLGA nanofibers with EGCG has not been reported yet. Herein, we explore the potential of EGCG-releasing fibrous membranes as alternative agents to decrease the incidence of postoperative adhesions.

\section{Materials and methods}

\section{Preparation of nanofiber membranes}

PLGA $(85: 15[\mathrm{~mol} / \mathrm{mol}]$, molecular weight $(\mathrm{MW})=$ $130-150 \mathrm{kDa})$ resins were kindly supplied by BMG Inc. (Kyoto, Japan). EGCG-releasing PLGA (E-PLGA) nanofiber membranes were prepared by an electrospinning method. PLGA resins were dissolved in the solvent system consisting of dichloromethane (Sigma-Aldrich Co., St Louis, MO, USA) and trifluoroethanol (Sigma-Aldrich Co.) with 8:2 ratio determined by optimization. The admixture $(2,4$ and $8 \mathrm{wt} \%)$ of EGCG (MW $=458.4$, Teavigo ${ }^{\mathrm{TM}}$; DSM Nutritional Products Ltd., Basel, Switzerland) was obtained by dissolving it in hexafluoroisopropanol (Sigma-Aldrich Co.). The mixed solution of PLGA and EGCG was loaded in a $10 \mathrm{~mL}$ syringe equipped with a blunt 23 -gauge needle. The electrospinning system consists of a syringe pump (single-syringe infusion pump; KD Scientific, Holliston, MA, USA) with a $10 \mathrm{~mL}$ syringe, a silicone hose, a stainless steel needle with an inner diameter of $0.8 \mathrm{~mm}$, a high-voltage power supply (NanoNC, Seoul, Republic of Korea) and a thin aluminum foil acting as a collector, which was positioned horizontally and grounded. Under ambient conditions, the electrospinning process was performed to fabricate E-PLGA nanofibers loaded with 2, 4, and $8 \mathrm{wt} \%$ EGCG (hereafter, E(2)-PLGA, E(4)-PLGA, and $\mathrm{E}(8)-\mathrm{PLGA}$, respectively). A positive voltage of $18 \mathrm{kV}$, a flow rate of $1 \mathrm{~mL} /$ hour, and a $12 \mathrm{~cm}$ distance between the needle tip and the collecting plate were used for this process. Following the spinning process, electrospun membranes were dried at room temperature for 6 hours and then placed at $50^{\circ} \mathrm{C}$ overnight. For physicochemical characterizations, prepared membranes were cut into discs of $12 \mathrm{~mm}$ in diameter and about $200 \mu \mathrm{M}$ in thickness, which weighed approximately $2.9 \mathrm{mg}$. Membranes for the in vitro bioactivity evaluation and in vivo animal study were prepared as sheets of $15 \times 15 \mathrm{~mm}$ in dimension and about $5.8 \mathrm{mg}$ in weight, with almost the same thickness as discs. Thus, approximately $230 \mu \mathrm{g}$ $(8 \mathrm{wt} \%, \approx 500 \mu \mathrm{mol})$ and $460 \mu \mathrm{g}(8 \mathrm{wt} \%, \approx 1,000 \mu \mathrm{mol})$ EGCG were loaded in one E(8)-PLGA disc and sheet, respectively. All discs and sheets made from E-PLGA nanofibers were sterilized by $\gamma$-irradiation $(2.5 \mathrm{Mrad})$ prior to use.

\section{Physicochemical characterizations of E-PLGA nanofiber membranes}

\section{Atomic force microscopy}

The topography of PLGA and E-PLGA membranes was characterized by atomic force microscopy (AFM) (noncontact mode, PSIA XE-100; PSIA Inc., Fremont, CA, USA) with a Multi 75 silicon scanning probe.

\section{Raman spectroscopy}

In order to confirm the dispersive loading of EGCG in E-PLGA membranes, Raman spectra of PLGA and E-PLGA membranes were obtained by Macro Probe Raman Measurement System (Ramboss-500i; Dongwoo Optron Co., Ltd, Gwangju-si, Republic of Korea) equipped with a thermoelectric-cooled charge-coupled device detector.

\section{In vitro EGCG release from E-PLGA nanofiber membranes}

E-PLGA discs were immobilized to the bottom of a glass vial by using sterile vacuum grease and then incubated 
in Dulbecco's phosphate-buffered saline (DPBS, pH 7.4; Sigma-Aldrich Co.) at $37^{\circ} \mathrm{C}$ for 28 days. At the end of each predetermined incubation period, the absorbance was quantified at $275 \mathrm{~nm}$ by an ultraviolet spectrophotometer (U-2800A; Hitachi Ltd., Tokyo, Japan). Cumulatively released EGCG from E-PLGA discs was calculated through the standard calibration curve of EGCG solution (Figure S1).

\section{In vitro degradation of E-PLGA nanofiber membranes}

Cumulative weight loss was used as an index of PLGA degradation in vitro. An initial weight of either PLGA or E-PLGA disc was weighed using an analytical balance (Ohaus Adventurer; Ohaus, Parsippany, NJ, USA). All weighed discs were immersed in $3 \mathrm{~mL}$ DPBS ( $\mathrm{pH}$ 7.4) and incubated in a bioshaker (BR-4OLF; Taitec Corporation, Saitama, Japan) at $37^{\circ} \mathrm{C}$ with shaking at $60 \mathrm{rpm}$ for up to 8 weeks and medium was refreshed every week. The $\mathrm{pH}$ of the solution was monitored over time to ensure that a stable $\mathrm{pH} 7.4$ was maintained at all times. At determined time intervals, immersed discs were retrieved, washed with distilled water and dried in a vacuum desiccator for 24 hours at room temperature. Immediately after vacuum-drying, the weight of discs was measured by using the balance. The cumulative weight loss of PLGA and E-PLGA discs was determined as percentage $(\%)$ of the dry weight of each disc at each time divided by its initial dry weight.

\section{Mechanical test}

In order to evaluate the influence of EGCG blending on the mechanical properties of PLGA nanofiber membranes, the tensile strengths at break of PLGA and E-PLGA membranes were measured. The dimensions of all testing specimens were prepared according to the guidelines of the American Society for Testing and Materials (D-638 and D-882) for the uniaxial tensile strength testing. ${ }^{16}$ The tensile strength at break was determined using Autograph AG-20kNG (Shimadzu, Kyoto, Japan). A displacement of $1 \mathrm{~mm} /$ minute was applied to each specimen along with the longitudinal direction, and all data were collected at a frequency of $20 \mathrm{~Hz}$ until break occurred.

\section{Reactive oxygen species levels by assay}

The $2^{\prime}, 7^{\prime}$-dichlorodihydrofluorescein (DCF) assay is a widely used method to detect reactive oxygen species (ROS) levels in pharmacological studies. ${ }^{17,18}$ The amount of potential free radicals was quantified using an ROS assay kit (OxiSelect ${ }^{\mathrm{TM}}$; Cell Biolabs, Inc., San Diego, CA,
USA), which employs the cell-permeable fluorogenic probe $2^{\prime}, 7^{\prime}$-dichlorodihydrofluorescein diacetate (DCFH-DA). DCFH-DA is an ROS detector that can cross cell membranes and be deacetylated by intracellular esterases to nonfluorescent $2^{\prime}, 7^{\prime}$-dichlorodihydrofluorescein (DCFH). In the presence of ROS, DCFH is rapidly oxidized to the highly fluorescent DCF, which is readily detectable. The fluorescence intensity is proportional to the ROS levels within the cell cytosol.

For preparing the extracts of PLGA and E-PLGA nanofibers, each sheet was incubated for 3 days in DPBS (pH 7.4) at $37^{\circ} \mathrm{C}$. L-929 cells (a murine fibroblast cell line, CCL-1; American Type Culture Collection, Manassas, VA, USA) were routinely maintained in a complete Dulbecco's Modified Eagle's Medium (Sigma-Aldrich Co.) supplemented with 10\% fetal bovine serum (Sigma-Aldrich Co.) and $1 \%$ antibiotic antimycotic solution (including 10,000 U penicillin, $10 \mathrm{mg}$ streptomycin, and $25 \mu \mathrm{g}$ amphotericin $\mathrm{B}$ per $\mathrm{mL}$; Sigma-Aldrich Co.) at $37^{\circ} \mathrm{C}$ in a humidified atmosphere of $5 \% \mathrm{CO}_{2}$ in air. Cells, grown to $70 \%-80 \%$ confluent monolayers, were pretreated with or without $50 \mu \mathrm{M} \mathrm{H}_{2} \mathrm{O}_{2}$ for 30 minutes and then exposed to $50 \%$ diluted extract of either PLGA or E-PLGA sheet for 23 hours at $37^{\circ} \mathrm{C}$ in a $\mathrm{CO}_{2}$ incubator. Afterwards, the cell cultures were further incubated with DCFH-DA for 30 minutes at $37^{\circ} \mathrm{C}$ in the dark. Parallel sets of wells containing vehicle-treated cells were regarded as the negative controls. The fluorescence emission of DCF was monitored at an excitation wavelength of $480 \mathrm{~nm}$ and an emission wavelength of $530 \mathrm{~nm}$ in a fluorescence plate reader (VICTOR ${ }^{3}$ Multilabel Counter; PerkinElmer, Inc., Waltham, MA, USA). The amount of DCF formed was calculated from a calibration curve constructed using an authentic DCF standard. The relative DCF fluorescence intensity was calculated as a percentage of the DCF formed in negative control wells.

\section{Activated partial thromboplastin time measurement}

The antithrombogenicity of E-PLGA nanofibers was evaluated by determining activated partial thromboplastin time (aPTT). Citrated, platelet-poor plasma (PPP) was prepared from peripheral venous blood collected by clean, nontraumatic venipuncture directly into a polystyrene tube containing $0.12 \mathrm{M}$ trisodium citrate at a ratio of 9:1 and then centrifuged at 2,200 $\mathrm{g}$ for 10 minutes. The processed plasma was frozen and stored at $-70^{\circ} \mathrm{C}$. Immediately before testing, the PPP was thawed in a water bath at $37^{\circ} \mathrm{C}$. According to the same process as described above, $50 \%$ diluted extracts in DPBS 
( $\mathrm{pH}$ 7.4) of PLGA and E-PLGA sheets were prepared and then added to the thawed plasma. An aPTT reagent (APTT lyophilized silica, HemosIL ${ }^{\text {TM}}$; Instrumentation Laboratory, Bedford, MA, USA) was used as follows: $0.1 \mathrm{~mL}$ of the reagent was mixed with the admixture of $0.1 \mathrm{~mL}$ PPP and diluted extracts and then incubated for 5 minutes at $37^{\circ} \mathrm{C}$; and $0.1 \mathrm{~mL}$ of prewarmed calcium chloride $(0.025 \mathrm{~mol} / \mathrm{L})$ was added and mixed, at which time the timer was started. Coagulation times (aPTT) were determined with a coagulometer (IL ACL-300; Instrumentation Laboratory). Normal saline $(0.9 \% \mathrm{NaCl})$ and heparin $(0.1 \mathrm{U} / \mathrm{mL})$ were employed as the negative and positive controls, respectively. Normal values of aPTT are reported as 24-37 seconds. ${ }^{19}$

\section{Animal study for antiadhesion efficacy of E-PLGA nanofiber membranes}

\section{Animals and experimental groups}

Male adult (10-week-old) specific-pathogen-free Sprague Dawley rats (Samtaco Bio, Osan-si, Republic of Korea) weighing approximately $350 \mathrm{~g}$ each were individually housed in metabolic cages for 3 days before surgical treatment and until the day of sacrifice. They were given food and water ad libitum both preoperatively and postoperatively. All experiments were performed between the hours of 9 am and 5 pm. Animal care followed the criteria of the Animal Care Committee of Yonsei University College of Medicine for the care and use of laboratory animals in research. All experiments related to surgical procedures and treatments were performed in accordance with the guidelines of the Animal Experiment and Ethics Committee of Yonsei University College of Medicine. Rats were randomly divided into four experimental groups: Group I, rats treated without any antiadhesion agents (untreated controls); Group II, rats treated with pure PLGA membranes; Group III, rats treated with E(8)-PLGA membranes; and Group IV, as the positive control, rats treated with membranes of oxidized regenerated cellulose (Gynecare Interceed ${ }^{\circledR}$; Ethicon Inc., Somerville, NJ, USA). Antiadhesion studies were carried out in 12 animals for each group.

\section{Surgical procedures and treatments}

\section{for antiadhesion study}

Sterile surgical technique was applied throughout the study. Animals were anesthetized by intraperitoneal injection with a mixture of 35-50 mg/kg ketamine $\mathrm{HCl}$ (Huons Co., Ltd., Seongnam-si, Republic of Korea) and 2\% xylazine hydrochloride (Rompun ${ }^{\circledR}$; Bayer AG, Leverkusen, Germany) before the celiotomy. After anesthetic induction, an area (about $15 \mathrm{~cm}^{2}$ ) in the skin of the abdomen was shaved and swabbed with alcohol and povidone iodine solutions. A longitudinal incision ( $5 \mathrm{~cm}$ long) was made using a blade (No. 11), and both abdominal walls (right and left side) were reflected and similar adhesion models were made on each of the abdominal walls. Abdominal walls were exposed and then a $10 \mathrm{~mm} \times 10 \mathrm{~mm}$ of abdominal wall muscle away from the incision site was excised to exfoliate the peritonea until collagen was exposed, which formed small rectangles with roughly the same size. Tweezers were covered with gauze, and the outer surfaces of the internal organs exactly facing this defective abdominal wall area were abraded/brushed gently to trigger the adhesion process between these defective surfaces. After that, one membrane (experimental group) with a size of $15 \mathrm{~mm} \times 15 \mathrm{~mm}$ was fixed with 6-prolene suture, at four corners on the right side of the abdominal wall, to cover the injured area. The left side of the abdominal wall was defective in a similar procedure, but left alone (ie, no membrane fixed), which served as control. Then, the middle line incision was closed using 4-0 silk suture. After 1 week, rats were euthanized and their abdominal cavities reopened by two other surgeons who were blind tested to evaluate the incidence and severity of postsurgical surgical adhesion based on adhesion score systems as described in Table 1.

Table I Adhesion score systems for macroscopic evaluations

\begin{tabular}{lll}
\hline Adhesion scoring system & Score & Criteria \\
\hline Extent of adhesions & 0 & No adhesion \\
& I & $1 \%-25 \%$ involvement \\
& 3 & $26 \%-50 \%$ involvement \\
& 4 & $51 \%-75 \%$ involvement \\
Severity of adhesions & 0 & No adhesion \\
& I & Tiny filmy adhesions easy to separate without tension or injury of the involved tissues \\
& 2 & Dense adhesions that require tension to divide \\
& 3 & Dense adhesions that lead to serosal injury during lysis or that need to be divided with scissors \\
& 4 & Other intra-abdominal organs were involved, and a conglomerate was formed
\end{tabular}


The adhesion score system was adopted according to each adhesion criterion: the extent of adhesion, following the criteria of Leach et $\mathrm{al}^{20}$ and the severity of adhesion, following the criteria of Knightly et al. ${ }^{21}$ After scoring macroscopic adhesions, the adhesion site was excised enbloc with adhesive tissues or organs and was fixed in 10\% neutral buffered formalin for 24 hours, and segments were stained with hematoxylin and eosin. Microscopic grades for inflammation, neovascularization, fibrosis, and fatty infiltrate were graded from $0-3$ as follows: 0 , none; 1 , mild; 2 , moderate; and 3 , dense, as previously described. ${ }^{22}$ The histopathologist who assessed each specimen was blinded to the information.

\section{Statistical analysis}

All variables were tested in three independent experiments in vitro, which was repeated twice $(n=6)$. Quantitative data are expressed as mean \pm standard deviation (SD). Data were tested for homogeneity of variances using the test of Levene, prior to statistical analysis. Statistical comparisons were carried out with a one-way analysis of variance (ANOVA; SAS Institute Inc., Cary, NC, USA), which was followed by the Bonferroni test for multiple comparisons. Statistical analysis for the animal study was made by using the Kruskal-Wallis one-way ANOVA and Mann-Whitney $U$-test. A value of $P<0.05$ was considered statistically significant.

\section{Results and discussion Physicochemical characteristics of E-PLGA nanofiber membranes}

Electrospinning techniques can fabricate fibrous scaffolds with excellent biocompatibility and biodegradability, as well as suitable microstructure/nanostructure to guide tissue regeneration and to incorporate bioactive molecules such as drugs, proteins, and genes. ${ }^{23-25}$ E-PLGA nanofiber membranes were prepared by electrospinning PLGA with 2,4 , and $8 \mathrm{wt} \%$ EGCG and were seen to be slightly yellowish red-colored due to loaded EGCG (Figure S2). The physicochemical properties of E-PLGA membranes were characterized by AFM, Raman spectroscopy, and EGCG release and degradation profiles.

AFM demonstrated that E-PLGA membranes had a three-dimensional interconnected pore structure with randomly oriented nanofibers (Figure 1A). The average fiber diameter of E-PLGA membranes was found to range between 300-500 nm and to be almost similar to that of pure PLGA equivalents. Raman spectra of pure PLGA and E-PLGA membranes were dominated by the noticeable band near $1,768 \mathrm{~cm}^{-1}$ (Figure 1B), which was due to the ester linkage of PLGA. ${ }^{26}$ The deformation band of $\mathrm{CH}_{3}$ was observed at $1,450 \mathrm{~cm}^{-1}$, which corresponds to the antisymmetric vibration of $\mathrm{CH}_{3}$ from the lactic unit of PLGA. ${ }^{26}$ Also, quite intense and definite bands were found at $1,046 \mathrm{~cm}^{-1}$ and $1,127 \mathrm{~cm}^{-1}$ for the C-CH ${ }_{3}$ of PLGA. In E-PLGA membranes, the characteristic bands were found near $1,640 \mathrm{~cm}^{-1}$ and $3,450 \mathrm{~cm}^{-1}$, which are derived from the $\mathrm{C}=\mathrm{O}$ and ring $\mathrm{OH}$ stretching vibrations of EGCG, respectively. ${ }^{27}$ This result indicates that EGCG was well dispersed in the E-PLGA fiber.

The EGCG release profiles were examined to determine whether EGCG could be released from E-PLGA membranes in amounts necessary to generate effective concentrations that prevent postsurgical adhesions. As shown in Figure 1C, EGCG was released in a logarithmic manner in which the release rate decreased with time. A minor burst effect of less than $10 \%(\leq 50 \mu \mathrm{M})$ of loaded amounts was observed during the first day of release from E(8)-PLGA membranes. After 7 days, E(8)-PLGA membranes showed the sustained release of EGCG. From the release profile, it was found that about $180 \mu \mathrm{M}$ and $240 \mu \mathrm{M}(\approx 36 \%$ and $48 \%$ of loaded amounts) EGCG was cumulatively released from E-PLGA at 7 days and 28 days, respectively. In the cases of E(2)-PLGA and E(4)-PLGA membranes, the release patterns were similar to that of E(8)-PLGA membranes, whereas the cumulatively released concentrations $(\approx 14 \%$ and $70 \mu \mathrm{M}$ for $\mathrm{E}(2)$ PLGA membranes and $\approx 16 \%$ and $80 \mu \mathrm{M}$ for E(4)-PLGA membranes) at 7 days were too low to reduce the adhesion formation. It is considered that the main release mechanism during the test period might be controlled diffusion of EGCG together with PLGA degradation. ${ }^{28}$

Figure 2A shows the cumulative weight loss of E-PLGA nanofiber membranes. The in vitro degradation profiles of E-PLGA membranes showed the stepwise patterns as follows. In the first step, for the period up to 1 week of incubation, E-PLGA membranes exhibited a very fast weight loss rate (about $3 \%$ and $8 \%$ loss of the initial weight $\mathrm{E}(2$ or 4)-PLGA and E(8)-PLGA, respectively). After that period, the mass loss was decelerated until reaching the plateau at 2 weeks or 4 weeks. In the second step, the degradation was reaccelerated and additional weight loss of more than $8 \%$ was observed in E(4)-PLGA and E(8)-PLGA membranes at 8 weeks. Different from that of E-PLGA membranes, the mass loss of pure PLGA equivalents was insignificant during test periods. Aliphatic polyesters such as poly(glycolic acid), PLA, and PCL are known to be degraded by nonenzymatic random hydrolytic scission of esters linkage. ${ }^{29}$ The mass loss of E-PLGA membranes during incubation is considered to be more accelerated by the release of EGCG 
A
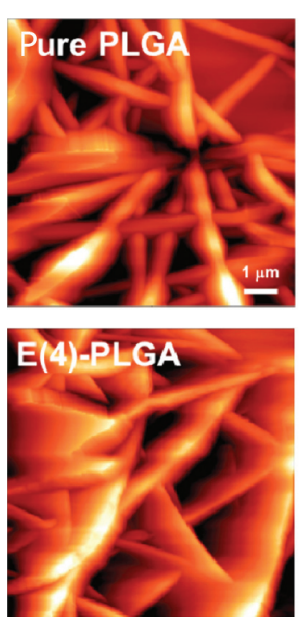
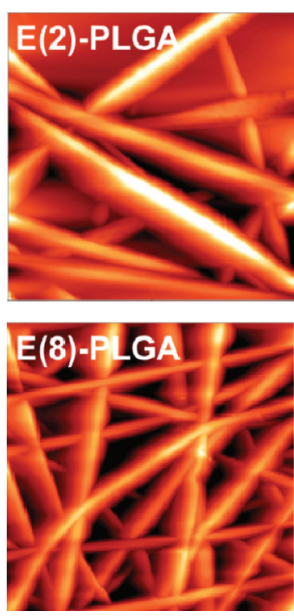

C
B

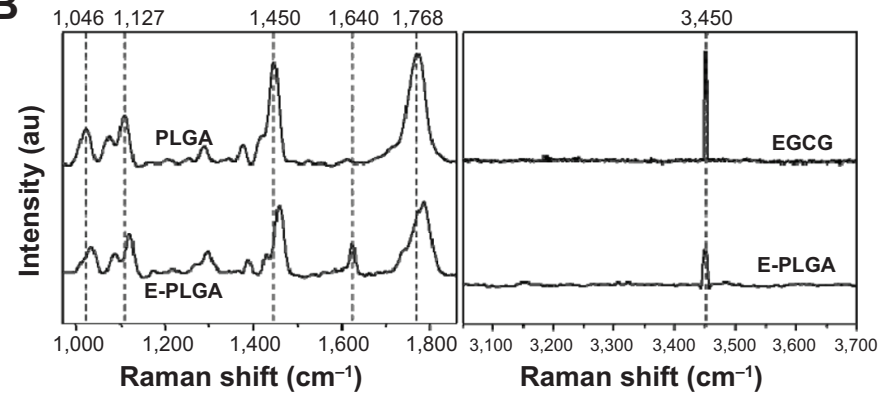

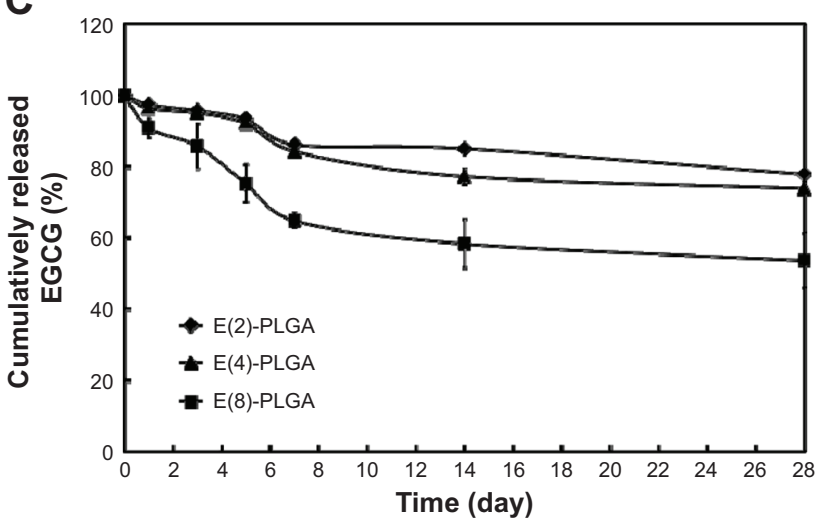

Figure I Physicochemical properties of E-PLGA nanofiber membranes.

Notes: (A) AFM images, (B) Raman spectra, and (C) in vitro release profiles of EGCG from E-PLGA membranes. All photographs shown in this figure are representative of six independent experiments with similar results.

Abbreviations: AFM, atomic force microscopy; au, arbitrary unit; EGCG, epigallocatechin-3-O-gallate; E-PLGA, EGCG-releasing PLGA; PLGA, poly(lactic-co-glycolic acid).

from E-PLGA matrices. This E-PLGA degradation profile closely matches that of EGCG release and supports its release mechanism.

The morphological changes of pure PLGA, E(2)-PLGA and $\mathrm{E}(8)$-PLGA membranes during in vitro degradation are shown in Figures 2B-D. No significant morphological changes in pure PLGA membranes were observed at 2 weeks of incubation (Figure 2B). The small change in morphology during this period is also consistent with the small amount of shrinkage of the membrane. It was not until 8 weeks that the fibers started to break down into small pieces. However, the morphologies of E-PLGA membranes were significantly changed with the breakdown of the fibers into small pieces at the first week of incubation (Figures 2C and D). After 4 weeks, the degradation was more accelerated and most of the fibrous morphologies disappeared, with only chunks of degraded materials left. These phenomena can be explained by the fact that, due to unique nanofiber morphology with extremely high surface area to volume ratio, the water absorption capacity of electrospun PLGA membranes is much larger than that of cast solid (nonfibrous) films. ${ }^{30}$ These morphological observations agreed well with the quantitative degradation profiles.

\section{Mechanical properties of E-PLGA nanofiber membranes}

Biomechanical analysis revealed that EGCG did not alter the tensile strength of PLGA nanofiber membranes but substantially affected the elastic modulus (Em) of PLGA membranes (Figure 3). The Em of PLGA membranes was significantly $(P<0.05)$ decreased by EGCG blending, while their strain at break was significantly $(P<0.05)$ increased, suggesting that EGCG makes PLGA membranes less elastic but more plastic. This result was completely different from that observed with the cast solid film. ${ }^{16}$ Generally, the Em reflects elasticity, which tends to return the polymeric material to its original form after deformation. Higher values of Em are associated with greater stiffness of the polymer. It is thus considered that upon EGCG addition, fibrous 


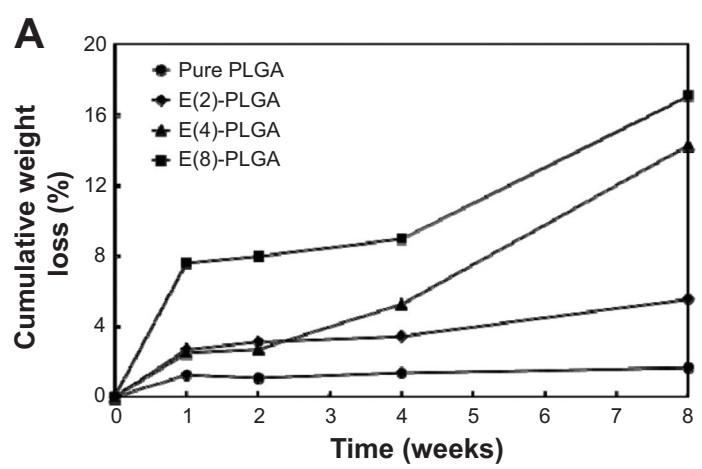

B
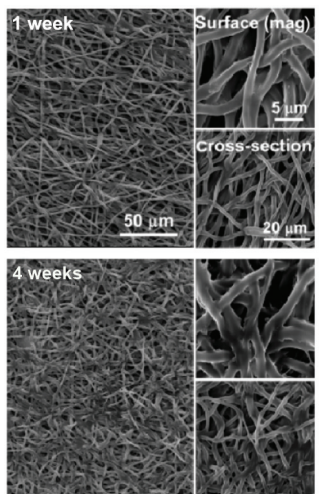

$\mathrm{D}_{1}$
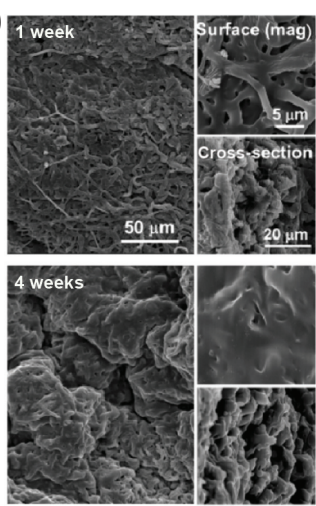
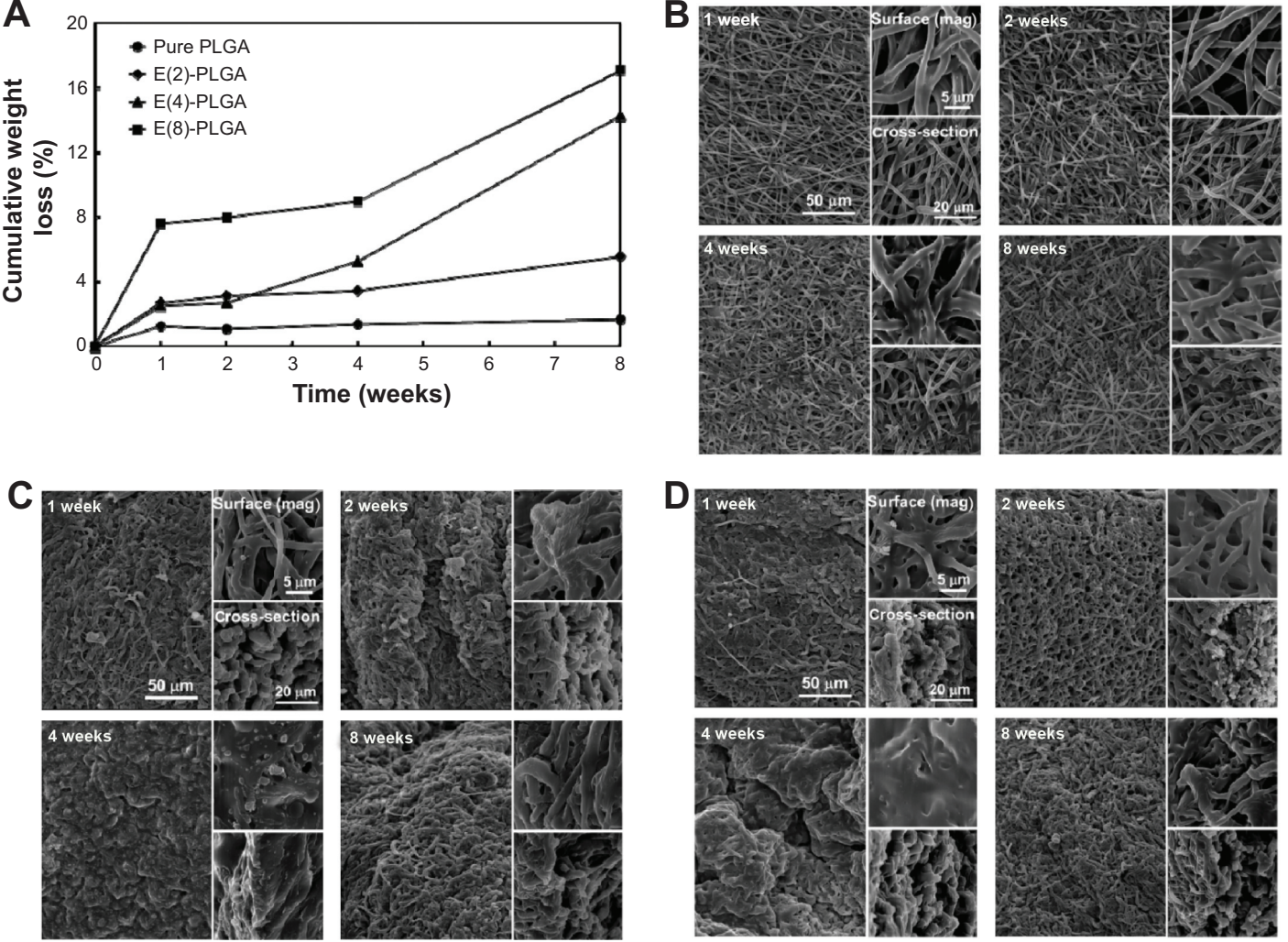
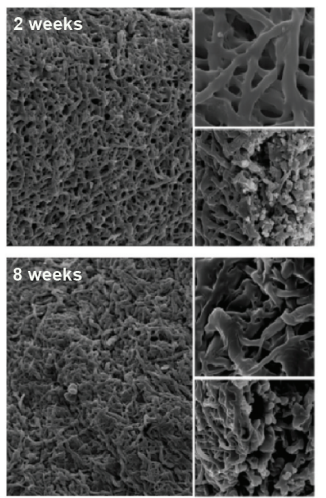

Figure 2 Effects of EGCG blending on degradation of PLGA nanofiber membranes.

Notes: (A) In vitro degradation profile and scanning electron micrographs of (B) pure PLGA, (C) E(2)-PLGA, and (D) E(8)-PLGA membranes. Abbreviations: EGCG, epigallocatechin-3-O-gallate; E-PLGA, EGCG-releasing mag, magnification; PLGA; PLGA, poly(lactic-co-glycolic acid).
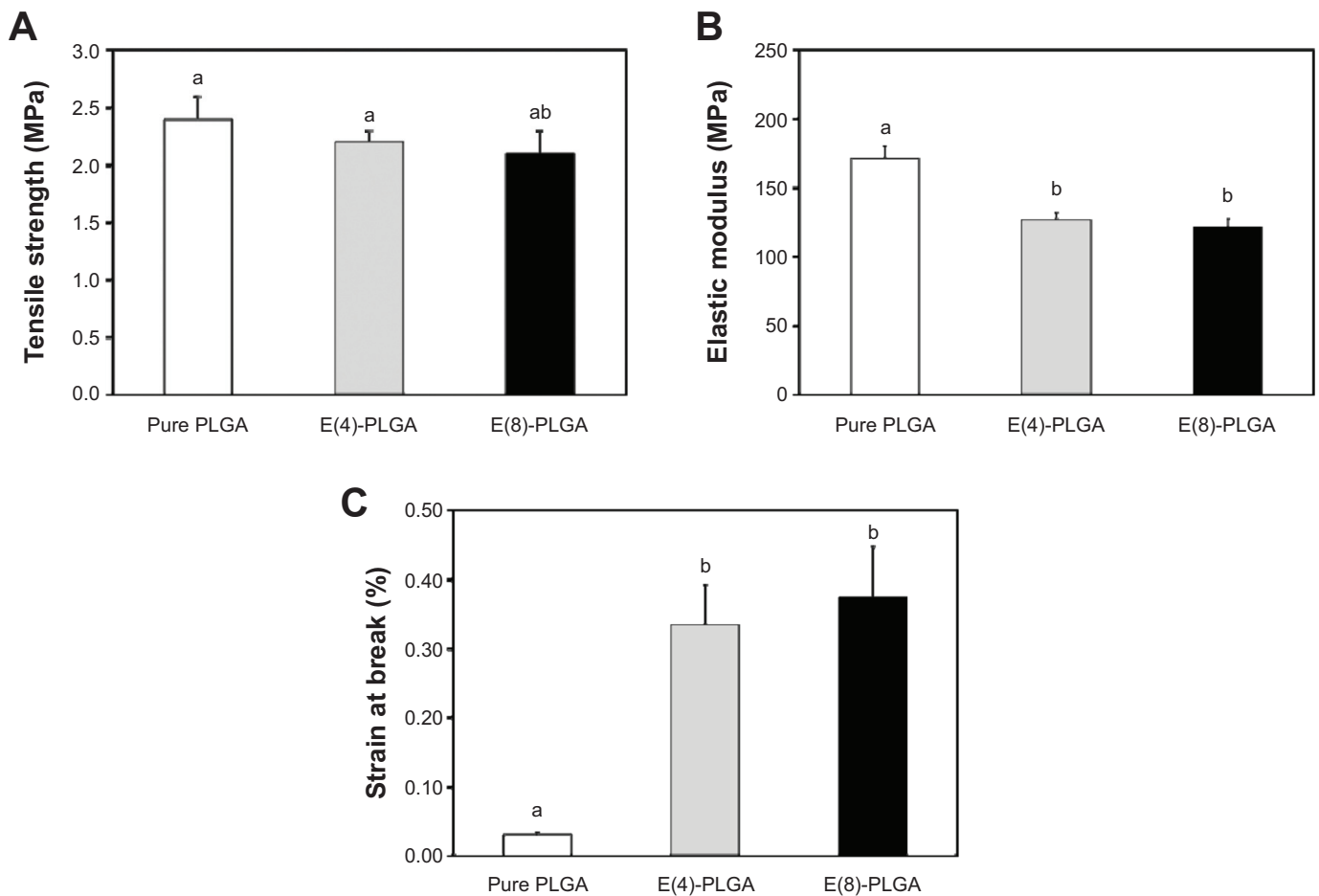

Figure 3 Mechanical properties of E-PLGA nanofiber membranes.

Notes: $(\mathbf{A})$ Tensile strength, $(\mathbf{B})$ elastic modulus, and $(\mathbf{C})$ strain at break. Different letters denote significant differences between the control and experimental groups, $P<0.05$. If two groups have the same single letter (a,b,c, etc), there is no significant difference between them. If a group is marked with a dual letter (eg, bc), it has significant difference from the control and another group marked with 'a', but does not from the other groups marked with 'b' or ' $c$ '.

Abbreviations: EGCG, epigallocatechin-3-O-gallate; E-PLGA, EGCG-releasing PLGA; PLGA, poly(lactic-co-glycolic acid). 
membranes have the tendency to be tougher but less hard, which is directly opposite to nonfibrous ones.

\section{In vitro antioxidant activity and hemocompatibility}

In order to investigate whether EGCG released from E-PLGA is effective in scavenging ROS, a DCF assay was performed. Injury to the skin, eg, surgical incision or wounds, initiates a series of events including inflammation, new tissue formation, and matrix remodeling. During the early inflammatory phase, neutrophils and macrophages infiltrate the wounded tissue. ${ }^{31}$ Once activated, they produce large amounts of ROS as part of the host defense mechanism against bacterial and fungal infection. Although this process is beneficial, increased levels of ROS, eg, $\cdot \mathrm{OH}$ and $\mathrm{H}_{2} \mathrm{O}_{2}$, can inhibit cell migration and proliferation and can even cause severe tissue damage. ${ }^{32,33}$ For the detoxification of these molecules, cells synthesize various types of ROS-scavenging (ie, antioxidant) enzymes. In addition, several studies have pointed to a role for ROS in postoperative adhesion formation, ${ }^{34}$ since the administration of ROS scavengers, such as catalase, superoxide dismutase, and trimetazidine, decreased adhesion formation in several animal models. ${ }^{32,33}$ As shown in Figure 4A, both pure PLGA and E-PLGA nanofiber membranes were shown to generate few, if any, ROS, but their ROS-scavenging ability was found to be very different from each other. It was revealed that the extract of E(8)-PLGA membranes significantly $(P<0.05)$ scavenged ROS derived from pretreated $\mathrm{H}_{2} \mathrm{O}_{2}$, which would adversely affect the cell viability, while that of pure PLGA equivalents did not exert any antioxidant activity. In the extract of E(4)-PLGA membranes, moderate effects were observed. From the release profile (Figure 1B), approximately $70 \mu \mathrm{M}(\approx 14 \%$ of loaded amounts) EGCG was estimated to be released from E-PLGA membranes during the 3-day period. This result implies that released EGCG would play a pivotal role in detoxifying ROS.

Postsurgical adhesion formation is regulated by peritoneal fibrinolysis, ${ }^{35,36}$ which is determined by tissue-type plasminogen activator as a thrombolytic (or fibrinolytic) agent and plasminogen activator inhibitor- $1 .{ }^{37}$ Suppression of inflammation, manipulation of coagulation, and direct augmentation of fibrinolytic activity may be promising antiadhesion treatment strategies. ${ }^{38}$ Thromboplastin, found especially in blood platelets, is a plasma protein that functions in the conversion of prothrombin to thrombin in blood coagulation (or thrombogenesis). The aPTT test was widely used for the clinical detection of the abnormality of blood plasma and for the primary screening of the anticoagulative chemicals. ${ }^{39}$ It was recently applied in the evaluation of the in vitro antithrombogenicity of biomaterials. ${ }^{40,41}$ The aPTT of pure PLGA and E-PLGA nanofiber membranes are presented in Figure 4B. The aPTT of E-PLGA membranes was significantly $(P<0.05)$ prolonged as compared to that of pure PLGA equivalents. E(4)-PLGA and E(8)-PLGA membranes showed about 57 seconds and 85 seconds of aPTT, respectively, which were 1.6-2.3 times longer than pure PLGA equivalents $(\approx 32$ seconds of aPTT). This result indicates that the activation of the intrinsic blood coagulation system was suppressed by antithrombotic activities of EGCG released from E-PLGA nanofiber membranes. ${ }^{42}$ It was reported that phenolics such as catechin, epicatechin, quercetin, and resveratrol increased fibrinolytic protein (tissue-type plasminogen activator and urokinase-type plasminogen activator) expression and surface-localized fibrinolytic activity in cultured human umbilical-vein endothelial cells. ${ }^{43}$ Thus, adhesion barriers with the more effective fibrinolytic activity might be the better prophylactic strategy against unwanted fibrotic tissues. ${ }^{44,45}$

\section{Macroscopic and microscopic evaluations on anti-adhesion efficacy of E-PLGA nanofiber membranes}

During the study period, there was no mortality in any group. Gross adhesion findings and the distribution of adhesion scores among control and experimental groups are shown in Figures $5 \mathrm{~A}$ and $\mathrm{B}$, respectively. The average scores regarding the extent of adhesion were $3.60 \pm 0.55,3.20 \pm 0.84$, $2.00 \pm 0.71$, and $1.80 \pm 0.45$ for Group I (untreated controls), Group II (pure PLGA membranes), Group III (E(8)-PLGA membranes) and Group IV (Interceed ${ }^{\circledR}$, the positive control), respectively (Figure 5B). Pure PLGA membranes (Group II) showed a tendency toward slightly lower adhesion extent than the untreated controls (Group I), but there was no significant difference between them. On the contrary, E(8)-PLGA membranes (Group III) had a significantly $(P<0.05)$ lower average adhesion extent score than pure PLGA equivalents, and the score was almost similar to that of the positive control $\left(\right.$ Interceed $\left.^{\circledR}\right)$.

The average scores regarding the severity of adhesion were $3.29 \pm 0.62,3.14 \pm 0.81,1.14 \pm 0.59$, and $0.81 \pm 0.42$ for Groups I-IV, respectively (Figure 5B). E(8)-PLGA membranes, but not pure PLGA equivalents, showed significantly $(P<0.05)$ less severe adhesion than untreated controls. The positive control also showed significantly $(P<0.05)$ lower adhesion severity scores than the other groups. Representative images 

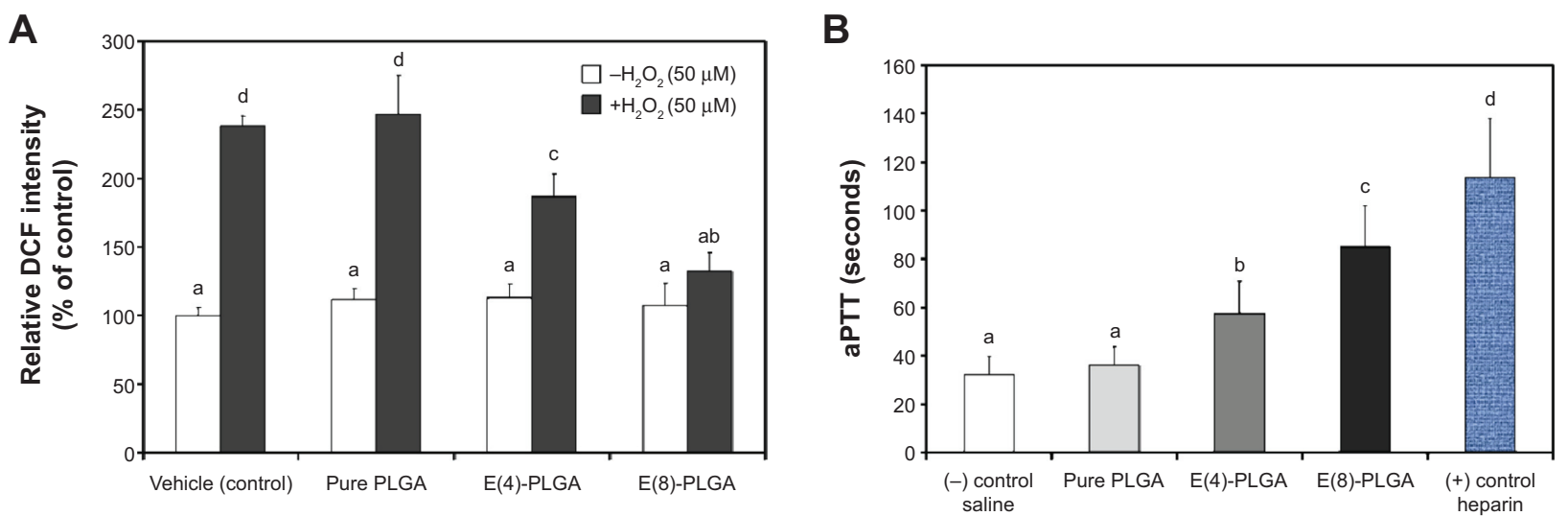

Figure $\mathbf{4}$ In vitro bioactivity of E-PLGA nanofiber membranes.

Notes: (A) Antioxidant activity from scavenged ROS levels and (B) hemocompatibility from extended aPTT. Different letters denote significant differences between the control and experimental groups, $P<0.05$.

Abbreviations: aPTT, activated partial thromboplastin time; DCF, 2',7'-dichlorodihydrofluorescein assay; EGCG, epigallocatechin-3-0-gallate; E-PLGA, EGCG-releasing PLGA; PLGA, poly(lactic-co-glycolic acid); ROS, reactive oxygen species.

A

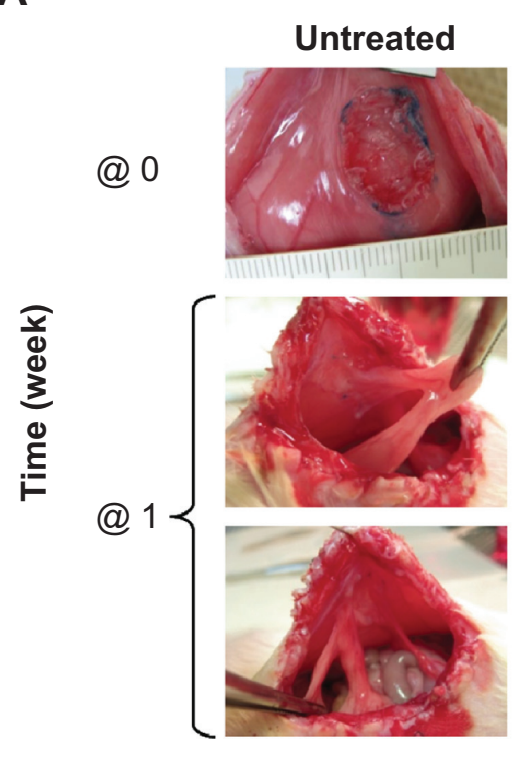

B

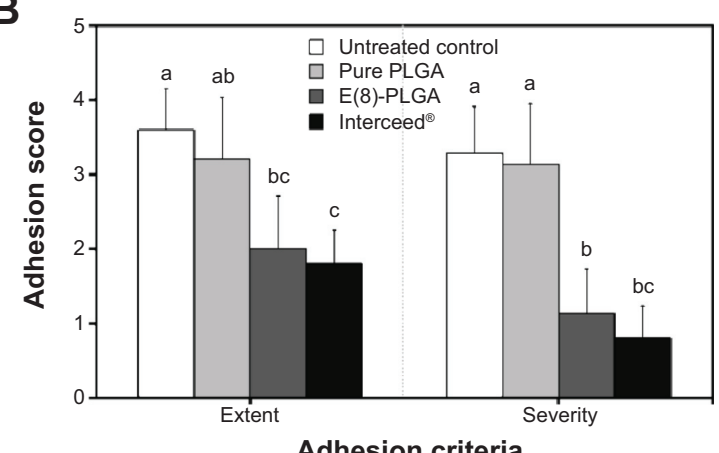

Pure PLGA
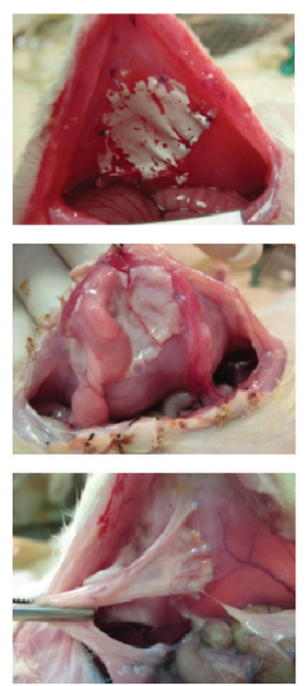

$E(8)-P L G A$
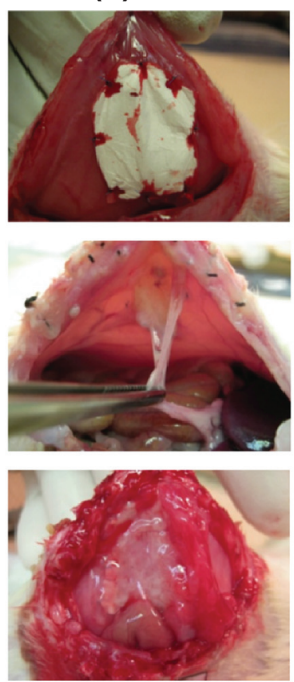

Interceed $^{\circledR}$
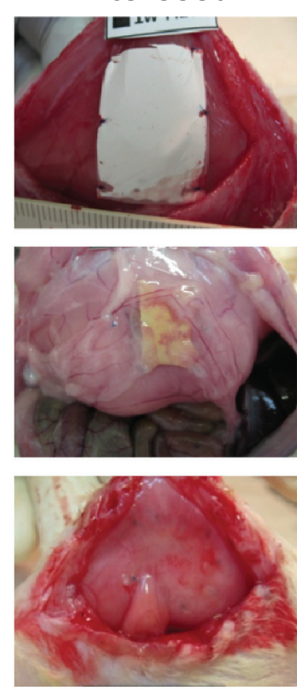

C

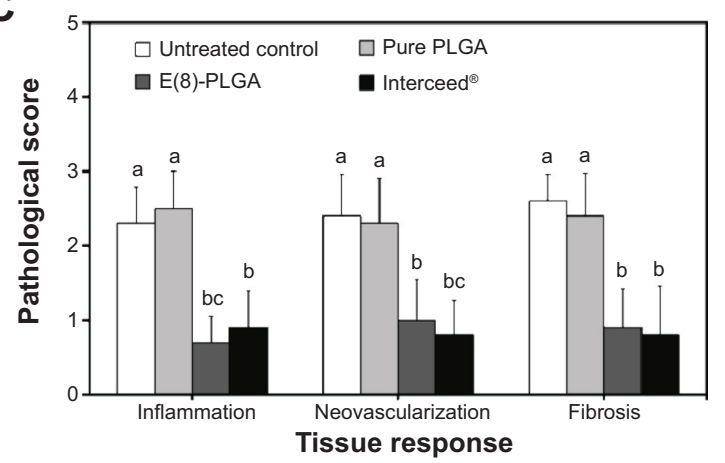

Figure 5 Gross findings of adhesions (A), comparisons of adhesion (extent and severity) scores (B), and histopathology (inflammation, neovascularization and fibrosis) scores (C) on postoperative week I.

Notes: In (A), Group I (untreated controls): extensive and severe adhesion was formed over the adhesion-inducing area. Group II (pure PLGA membranes): dense adhesion around and over the membrane was extensively seen, like the control group. Group III (E(8)-PLGA membranes): partial adhesion was confined to the adhesion-inducing area. Group IV (Gynecare Interceed ${ }^{\circledR}$; Ethicon Inc., Somerville, NJ, USA): a little, if any, adhesion occurred around the adhesion-inducing area. All photographs shown in this figure are representative of six independent experiments with similar results. In (B) and (C), data are expressed as mean \pm standard deviation on the basis of at least duplicate observations from 12 animals for each group. Different letters denote significant differences between the control and experimental groups, $P<0.05$. Abbreviations: EGCG, epigallocatechin-3-O-gallate; E-PLGA, EGCG-releasing PLGA; PLGA, poly(lactic-co-glycolic acid). 
for the most severe intra-abdominal adhesion in each group showed good agreement with the scores of the macroscopic adhesion (Figure 5A). Resultantly, E(8)-PLGA membranes showed significantly $(P<0.05)$ lower scores regarding both the extent and severity of adhesion than the untreated control and pure PLGA equivalents. However, no statistically significant difference was found between the untreated control group and pure PLGA membranes.

In terms of the extent and severity of adhesion, E(8)-PLGA membranes were found to have the potent ability to reduce abdominal adhesions, which was almost comparable to that of oxidized regenerated cellulose membranes (Interceed ${ }^{\circledR}$ ). In previous randomized controlled trials, Interceed ${ }^{\circledR}$ has already been shown to have the efficacy and safety for preventing postoperative abdominal adhesion; ${ }^{46,47}$ this potency was also confirmed in this study. In comparison to pure PLGA membranes, E(8)-PLGA membranes showed much better preventive effects of adhesion.

Histopathological scores for inflammation, neovascularization, and fibrosis from microscopic findings are shown in Figure 5C. Inflammation scores were 2.30 $\pm 0.49,2.50 \pm 0.50$, $0.70 \pm 0.35$, and $0.90 \pm 0.49$ for Groups I-IV, respectively. In particular, the E(8)-PLGA membrane (Group III) and Interceed $^{\circledR}$ (Group IV) had significantly $(P<0.05)$ fewer inflammatory responses responses and neovascularization than the other groups. However, no significant difference was noted between the control group and pure PLGA membrane

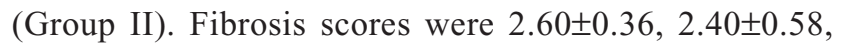
$0.90 \pm 0.52$, and $0.80 \pm 0.66$ for Groups I-IV, respectively. The degree of fibrosis was minimal in E(8)-PLGA membranes and Interceed ${ }^{\circledR}$, whereas confluent fibrosis with acute inflammation was evident in the other groups. Resultantly, it was revealed that the prophylactic effect of E(8)-PLGA membranes on the abdominal adhesion was comparable to that of a commercial tissue-adhesion barrier, Interceed ${ }^{\circledR}$. It is considered that EGCG released from E(8)-PLGA membranes exerted potent anti-inflammatory and antifibrotic activity to suppress the adhesion formation. In other antiadhesion studies using drug-impregnated physical barriers, paclitaxel-loaded hyaluronic acid films and sirolimus-eluting polypropylene meshes were shown to effectively prevent postsurgical adhesions. ${ }^{48,49}$ Even if both paclitaxel and sirolimus are potent antiproliferative drugs, their major problems are the frequency of tissue toxicity and hypersensitivity reactions. ${ }^{50,51}$ On the contrary, green tea catechin is regulated as a "generally regarded as safe" compound by the US Food and Drug Administration, and concentrated green tea polyphenols are classified as dietary supplements. ${ }^{52}$

\section{Conclusion}

From in vitro studies, it is confirmed that EGCG sustainedly released from biodegradable E-PLGA nanofiber membranes plays a key role in scavenging ROS and extending aPTT. These findings support a scenario in which on postoperative week 1 in the abdominal adhesion model, macroscopic adhesion (extent and severity) scores of E-PLGA membranes are significantly lower than those of PLGA equivalents without EGCG; the levels are almost comparable to those of commercialized membrane-type barrier $\left(\right.$ Interceed $^{\circledR}$ ), which has already been shown to have efficacy and safety for preventing postoperative abdominal adhesion. In conclusion, it is suggested that E-PLGA nanofiber membranes can safely reduce clinically relevant consequences of adhesions and may be effectively used in crafting strategies for the prevention of postsurgical adhesions without such problems as abdominal abscesses and anastomotic leaks, which may benefit patients.

\section{Acknowledgment}

This work was supported by the Convergence Research Grant funded by the Pusan National University (PNU, Convergence Research Grant) (PNU-2013-1313-0001).

\section{Disclosure}

The authors report no conflicts of interest in this work.

\section{References}

1. diZerega GS, Campeau JD. Peritoneal repair and post-surgical adhesion formation. Hum Reprod Update. 2001;7(6):547-555.

2. Alpay Z, Saed GM, Diamond MP. Postoperative adhesions: from formation to prevention. Semin Reprod Med. 2008;26(4):313-321.

3. Kamel RM. Prevention of postoperative peritoneal adhesions. Eur $J$ Obstet Gynecol Reprod Biol. 2010;150(2):111-118.

4. Holmdahl L. The role of fibrinolysis in adhesion formation. Eur J Surg Suppl. 1997;(577):24-31.

5. Liakakos T, Thomakos N, Fine PM, Dervenis C, Young RL. Peritoneal adhesions: etiology, pathophysiology, and clinical significance. Recent advances in prevention and management. Dig Surg. 2001;18(4): 260-273.

6. Hirschelmann A, Tchartchian G, Wallwiener M, Hackethal A, De Wilde RL. A review of the problematic adhesion prophylaxis in gynaecological surgery. Arch Gynecol Obstet. 2012;285(4):1089-1097.

7. Metwally M, Watson A, Lilford R, Vandekerckhove P. Fluid and pharmacological agents for adhesion prevention after gynaecological surgery. Cochrane Database Syst Rev. 2006;(2):CD001298.

8. Ahmad G, Duffy JM, Farquhar C, et al. Barrier agents for adhesion prevention after gynaecological surgery. Cochrane Database Syst Rev. 2008;(2):CD000475.

9. Maciver AH, McCall M, James Shapiro AM. Intra-abdominal adhesions: cellular mechanisms and strategies for prevention. Int J Surg. 2011;9(8):589-594.

10. Ward BC, Panitch A. Abdominal adhesions: current and novel therapies. J Surg Res. 2011;165(1):91-111.

11. Yang B, Gong C, Zhao X, et al. Preventing postoperative abdominal adhesions in a rat model with PEG-PCL-PEG hydrogel. Int $J$ Nanomedicine. 2012;7:547-557. 
12. Gao X, Deng X, Wei X, et al. Novel thermosensitive hydrogel for preventing formation of abdominal adhesions. Int $J$ Nanomedicine. 2013;8:2453-2463.

13. Zong X, Li S, Chen E, et al. Prevention of postsurgery-induced abdominal adhesions by electrospun bioabsorbable nanofibrous poly(lactideco-glycolide)-based membranes. Ann Surg. 2004;240(5):910-915.

14. Lee JH, Go AK, Oh SH, Lee KE, Yuk SH. Tissue anti-adhesion potential of ibuprofen-loaded PLLA-PEG diblock copolymer films. Biomaterials. 2005;26(6):671-678.

15. Hong Y, Fujimoto K, Hashizume R, et al. Generating elastic, biodegradable polyurethane/poly(lactide-co-glycolide) fibrous sheets with controlled antibiotic release via two-stream electrospinning. Biomacromolecules. 2008;9(4):1200-1207.

16. Han DW, Lee JJ, Jung DY, Park JC, Hyon SH. Development of epigallocatechin gallate-eluting polymeric stent and its physicochemical, biomechanical and biological evaluations. Biomed Mater. 2009;4(4): 044104.

17. Hong SC, Lee JH, Lee J, et al. Subtle cytotoxicity and genotoxicity differences in superparamagnetic iron oxide nanoparticles coated with various functional groups. Int J Nanomedicine. 2011;6:3219-3231.

18. Hong SW, Lee JH, Kang SH, et al. Enhanced neural cell adhesion and neurite outgrowth on graphene-based biomimetic substrates. Biomed Res Int. 2014;2014:212149.

19. Jordan CD, Flood JG, Laposata M, Lewandrowski KB. Case records of the Massachusetts General Hospital. Weekly clinicopathological exercises. Normal reference laboratory values. N Engl J Med. 1992;327(10): $718-724$

20. Leach RE, Burns JW, Dawe EJ, SmithBarbour MD, Diamond MP. Reduction of postsurgical adhesion formation in the rabbit uterine horn model with use of hyaluronate/carboxymethylcellulose gel. Fertil Steril. 1998;69(3):415-418.

21. Knightly JJ, Agostino D, Cliffton EE. The effect of fibrinolysin and heparin on the formation of peritoneal adhesions. Surgery. 1962;52:250-258.

22. Hwang HJ, An MS, Ha TK, et al. All the commercially available adhesion barriers have the same effect on adhesion prophylaxis?; a comparison of barrier agents using a newly developed, severe intra-abdominal adhesion model. Int $J$ Colorectal Dis. 2013;28(8):1117-1125.

23. Jin L, Wang T, Zhu ML, et al. Electrospun fibers and tissue engineering. J Biomed Nanotechnol. 2012;8(1):1-9.

24. Zamani M, Prabhakaran MP, Ramakrishna S. Advances in drug delivery via electrospun and electrosprayed nanomaterials. Int J Nanomedicine. 2013;8:2997-3017.

25. Rajangam T, An SS. Fibrinogen and fibrin based micro and nano scaffolds incorporated with drugs, proteins, cells and genes for therapeutic biomedical applications. Int J Nanomedicine. 2013;8:3641-3662.

26. Vey E, Rodger C, Booth J, Claybourn M, Miller AF, Saiani A. Degradation kinetics of poly(lactic-co-glycolic) acid block copolymer cast films in phosphate buffer solution as revealed by infrared and Raman spectroscopies. Polym Degrad Stab. 2011;96(10):1882-1889.

27. Calheiros R, Machado NFL, Fiuza SM, et al. Antioxidant phenolic esters with potential anticancer activity: a Raman spectroscopy study. J Raman Spectrosc. 2008;39(1):95-107.

28. Fredenberg S, Wahlgren M, Reslow M, Axelsson A. The mechanisms of drug release in poly(lactic-co-glycolic acid)-based drug delivery systems - a review. Int J Pharm. 2011;415(1-2):34-52.

29. Cho HH, Han DW, Matsumura K, Tsutsumi S, Hyon SH. The behavior of vascular smooth muscle cells and platelets onto epigallocatechin gallate-releasing poly(1-lactide-co-epsilon-caprolactone) as stentcoating materials. Biomaterials. 2008;29(7):884-893.

30. Zong X, Ran S, Kim KS, Fang D, Hsiao BS, Chu B. Structure and morphology changes during in vitro degradation of electrospun poly(glycolide-co-lactide) nanofiber membrane. Biomacromolecules. 2003;4(2):416-423.

31. Steiling H, Munz B, Werner S, Brauchle M. Different types of ROSscavenging enzymes are expressed during cutaneous wound repair. Exp Cell Res. 1999;247(2):484-494.
32. Bryan N, Ahswin H, Smart N, Bayon Y, Wohlert S, Hunt JA. Reactive oxygen species (ROS) - a family of fate deciding molecules pivotal in constructive inflammation and wound healing. Eur Cell Mater. 2012;24: 249-265.

33. Binda MM, Molinas CR, Koninckx PR. Reactive oxygen species and adhesion formation: clinical implications in adhesion prevention. Hum Reprod. 2003;18(12):2503-2507.

34. Awonuga AO, Belotte J, Abuanzeh S, Fletcher NM, Diamond MP, Saed GM. Advances in the pathogenesis of adhesion development: the role of oxidative stress. Reprod Sci. 2014;21(7):823-836.

35. Holmdahl LE, Al-Jabreen M, Risberg B. Role of fibrinolysis in the formation of postoperative adhesions. Wound Repair Regen. 1994;2(3): $171-176$.

36. Hatipoğlu A, Türkyilmaz Z, Mert S. The effects of melatonin on postoperative intraabdominal adhesion formation. Yonsei Med J. 2007; 48(4):659-664.

37. Shimomura M, Hinoi T, Ikeda S, et al. Preservation of peritoneal fibrinolysis owing to decreased transcription of plasminogen activator inhibitor-1 in peritoneal mesothelial cells suppresses postoperative adhesion formation in laparoscopic surgery. Surgery. 2013;153(3):344-356.

38. Hellebrekers BW, Kooistra T. Pathogenesis of postoperative adhesion formation. Br J Surg. 2011;98(11):1503-1516.

39. Kang IK, Kwon OH, Byun KH, Kim YH. Surface modification of polyetherurethaneureas and their antithrombogenicity. J Mater Sci Mater Med. 1996;7(3):135-140.

40. Sun YH, Feng LX, Zheng XX. New-type sulphonated polymer surface for improving blood compatibility. J Appl Polym Sci. 1999;74(12): 2826-2831.

41. Yuan W, Feng Y, Wang H, et al. Hemocompatible surface of electrospun nanofibrous scaffolds by ATRP modification. Mater Sci Eng C Mater Biol Appl. 2013;33(7):3644-3651.

42. Kang WS, Lim IH, Yuk DY, et al. Antithrombotic activities of green tea catechins and (-)-epigallocatechin gallate. Thromb Res. 1999;96(3): 229-237.

43. Abou-Agag LH, Aikens ML, Tabengwa EM, et al. Polyphyenolics increase t-PA and u-PA gene transcription in cultured human endothelial cells. Alcohol Clin Exp Res. 2001;25(2):155-162.

44. Hellebrekers BW, Trimbos-Kemper TC, Trimbos JB, Emeis JJ, Kooistra T. Use of fibrinolytic agents in the prevention of postoperative adhesion formation. Fertil Steril. 2000;74(2):203-212.

45. Aarons CB, Cohen PA, Gower A, et al. Statins (HMG-CoA reductase inhibitors) decrease postoperative adhesions by increasing peritoneal fibrinolytic activity. Ann Surg. 2007;245(2):176-184.

46. Reid RL, Hahn PM, Spence JE, Tulandi T, Yuzpe AA, Wiseman DM. A randomized clinical trial of oxidized regenerated cellulose adhesion barrier (Interceed, TC7) alone or in combination with heparin. Fertil Steril. 1997;67(1):23-29.

47. ten Broek RP, Stommel MW, Strik C, van Laarhoven CJ, Keus F, van Goor H. Benefits and harms of adhesion barriers for abdominal surgery: a systematic review and meta-analysis. Lancet. 2014;383(9911): 48-59.

48. Jackson JK, Skinner KC, Burgess L, Sun T, Hunter WL, Burt HM. Paclitaxel-loaded crosslinked hyaluronic acid films for the prevention of postsurgical adhesions. Pharm Res. 2002;19(4):411-417.

49. Maciver AH, McCall MD, Edgar RL, et al. Sirolimus drug-eluting, hydrogel-impregnated polypropylene mesh reduces intra-abdominal adhesion formation in a mouse model. Surgery. 2011;150(5):907-915.

50. Iwamoto T. Clinical application of drug delivery systems in cancer chemotherapy: review of the efficacy and side effects of approved drugs. Biol Pharm Bull. 2013;36(5):715-718.

51. Khalife WI, Kogoj P, Kar B. Sirolimus-induced alveolar hemorrhage. J Heart Lung Transplant. 2007;26(6):652-657.

52. Wu CD, Wei GX. Tea as a functional food for oral health. Nutrition 2002;18(5):443-444. 


\section{Supplementary materials}

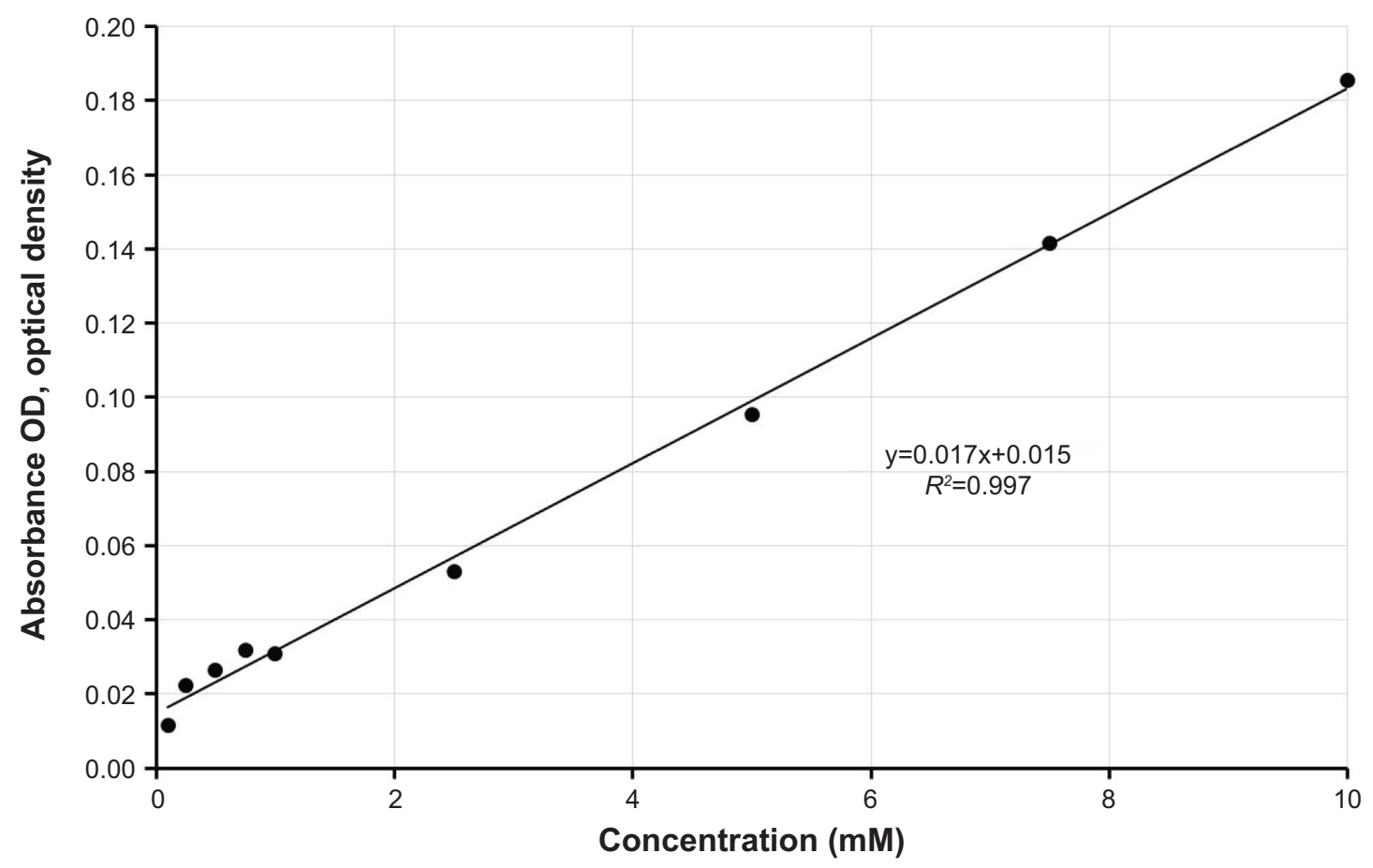

Figure SI Standard calibration curve for the quantification of EGCG concentration.

Abbreviations: EGCG, epigallocatechin-3-O-gallate; OD, optical density.
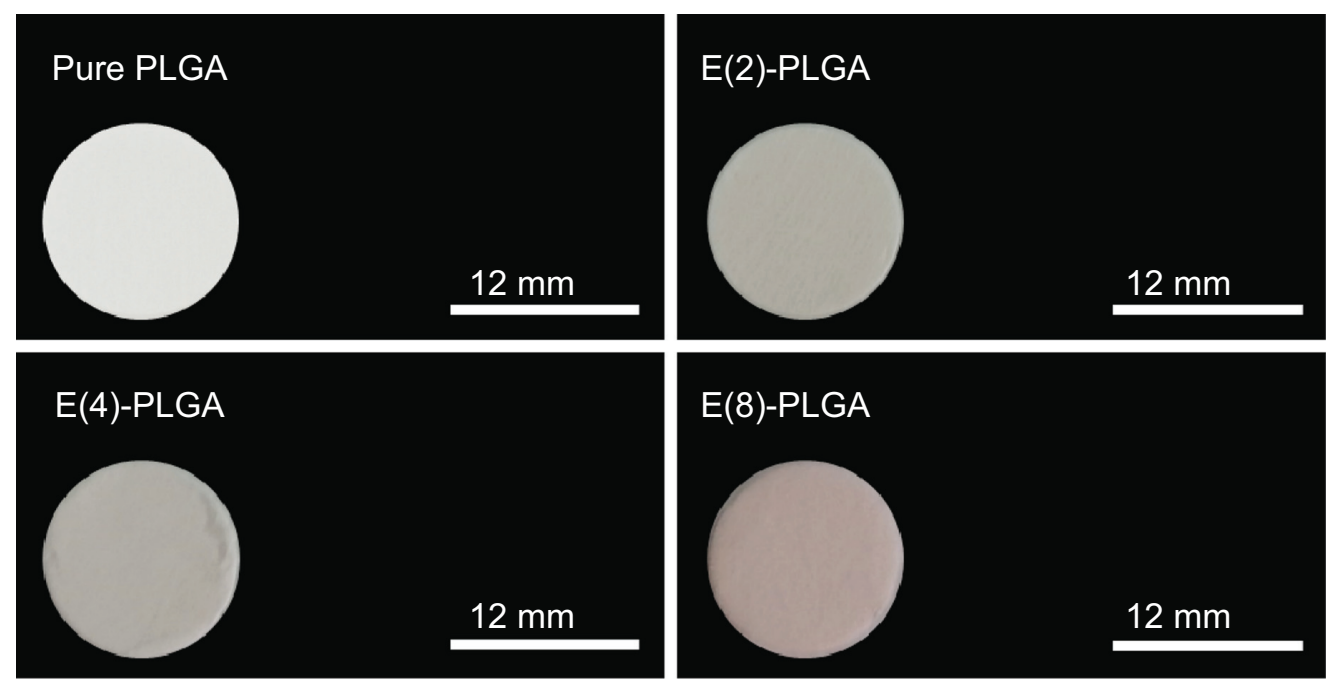

Figure S2 Digital photographic images of pure PLGA and E-PLGA membranes.

Abbreviations: EGCG, epigallocatechin-3-O-gallate; PLGA, poly(lactic-co-glycolic acid); E-PLGA, EGCG-releasing PLGA.

International Journal of Nanomedicine

\section{Publish your work in this journal}

The International Journal of Nanomedicine is an international, peerreviewed journal focusing on the application of nanotechnology in diagnostics, therapeutics, and drug delivery systems throughout the biomedical field. This journal is indexed on PubMed Central, MedLine, CAS, SciSearch ${ }^{\circledR}$, Current Contents ${ }^{\circledR} /$ Clinical Medicine,

\section{Dovepress}

Journal Citation Reports/Science Edition, EMBase, Scopus and the Elsevier Bibliographic databases. The manuscript management system is completely online and includes a very quick and fair peer-review system, which is all easy to use. Visit http://www.dovepress.com/ testimonials.php to read real quotes from published authors. 